\title{
A Comparative Study of Strategies for Translating Military Terms in the Complete English Versions of San Guo Yan Yi
}

\author{
Mingzhi Ran \\ School of Foreign Languages and Cultures \\ Panzhihua University \\ Panzhihua, China 617000
}

\begin{abstract}
San Guo Yan Yi is widely acknowledged as the first full-length romance novel of history that ever appeared in China and one of the "Four Great Chinese Classics". It also has a lot of military terms which carry unique Chinese cultural connotations. However, deeply rooted in traditional Chinese culture, those terms are likely to give rise to obstacles in translating, especially for translators whose cultural background differs greatly from what the novel is set. For this reason, this study attempts to compare strategies adopted to translate such military terms in the two complete English versions of San Guo Yan Yi. It is found that in translating the cultural elements of weapons, military attires, and military strategies, Brewitt-Taylor's version tends to be more domesticated, explicit and liberal to make the translated text more natural for target readers to enhances the acceptability of the translated text among the ordinary, while Roberts' version is more foreignized and faithful to make the translated text more informative for target readers, particularly scholarly ones to get a detailed picture of ancient Chinese culture, with the flavor and structure of the original text maintained to the largest extent.
\end{abstract}

Keywords-San Guo Yan Yi; military terms; translation strategies; comparative study

\section{INTRODUCTION}

The novel San Guo Yan Yi enjoys great popularity in Chinese literature as one of the Four Great Classics. It has been translated into nearly 20 different languages, and a large part of its existing versions are English translations. Up to now, it only has two complete English versions, with one, Romance of the Three Kingdoms, translated by Charles Henry Brewitt-Taylor, a customs officer in the late Qing Dynasty and the early stage of the Republic of China, and the other, Three Kingdoms, translated by Moss Roberts, a wellknown American Sinologist and a respected professor of East Asia Institute at New York University. There's no doubt that San Guo Yan Yi per se deserves meticulous research, considering the significant role it has played in Chinese literature. Its two complete English versions, as the crystallization of translators' painstaking efforts, are also worthy of studying.
Researchers have conducted studies on the translation of San Guo Yan Yi from different aspects. Ye Xicong (2011) analyzed the translation of war-related words in the two complete English versions of San Guo Yan Yi by means of C-E parallel corpus, with his focus on verbs that describe "personal actions" such as "斩", "砍", and war-related verbs and nouns such as "阵", "交锋". The analysis and findings are mainly based on precise statistical data, aided by translation theories of Newmark's and Nida's. Wang Shirong (2013), in one chapter of her dissertation, discusses the translation of "military culture" in San Guo Yan Yi from the following aspects: weapons, military inventions and tactics. Wang analyzes those aspects by means of textual criticism, which is to say, her main aim is to correct mistranslations in the existing versions. Chen Tian (2014) studied the English translation of culture-specific items in the two complete English versions of the Novel and concluded that in translating Chinese culture-specific items in San Guo Yan Yi, Brewitt-Taylor's version prefers to choose domestication while Roberts' version tends to adopt foreignization.

There are a lot of military terms in San Guo Yan Yi. These terms also carry unique Chinese cultural elements. However, deeply rooted in traditional Chinese culture, those terms are likely to give rise to obstacles in translating, especially for translators whose cultural background differs greatly from what the novel is set. For this reason, the study tries to explore and compare strategies employed for translating the military terms in the two complete English versions of San Guo Yan Yi.

To facilitate and systemize the study, such military terms are divided into three groups, namely weapons, military attires and military strategies. Moreover, the source text is hereinafter referred to as ST, and Brewitt-Taylor's version and Roberts' version are hereinafter referred to as T1 and T2 respectively.

\section{StRATEGIES FOR TRANSLATING WEAPONS}

In most cases, general weapon terms are translated literally into the same or similar weapon names in English, given the fact that the majority of weapon terms in San Guo $Y a n Y i$ can find their corresponding expressions in English. 
When the names stand for the weapons' power or status, As for the particular weapon of a renowned hero, things go two aspects: the first is the name of the weapon indicates its raw materials, length or shape; the second is the name stands for the weapon's power or status. In the first case, both translators tend to keep the original image first before they take their personal preferences into consideration. For example,

\section{Example 1:}

$\mathrm{ST}$ : 第一个, 右北平土根人, 姓程, 名普, 字德谋, 使一条铁脊 蛇矛, ……(第五回)

T1: Ch'eng P'u, whose weapon was an iron-spined snaky lance; ...

T2: Cheng Pu (Demou) from Tuyin in Youbeiping, wielding a steel-spined spear with snake-headed blade; ...

In this example, both translators have reproduced the image of "铁脊蛇矛" to the greatest extent, with "铁脊" being translated into "iron-spined" or "steel-spined", "蛇" into "snaky" or "snake" and "矛" into "lance" or "spear". However, in Brewitt-Taylor's version, "蛇" is used to modify the entire weapon, while Roberts paints a more detailed picture by emphasizing that it is the "blade" that imitates a snake head.

On the basis of literal translation, the two translators show interesting personal preferences as they render Chinese weapons into English: Brewitt-Taylor simplifies the details with generalized and plain modifiers based on his own reading experiences, while Roberts prefers to reproduce or even amplify the details according to his study on historical facts, as shown in the translation of Zhang Fei's weapon below ("Table I").

TABLE I. TRANSLATION OF ZHANG FEI'S WEAPON

\begin{tabular}{|l|l|l|}
\hline \multicolumn{1}{|c|}{ ST } & \multicolumn{1}{|c|}{ T1 } & \multicolumn{1}{c|}{ T2 } \\
\hline \multirow{4}{*}{ 丈八点钢矛 } & eighteen-foot spear & $\begin{array}{l}\text { eighteen-span spear of } \\
\text { tempered steel }\end{array}$ \\
\cline { 2 - 3 } & long spear & eighteen-span spear \\
\cline { 2 - 3 } & his father's long spear & eighteen-span spear \\
\hline 蛇矛丈八枪 & long snakelike spear & giant snake-head lance \\
\hline \multirow{5}{*}{ 丈八蛇矛 } & long spear & $\begin{array}{l}\text { eighteen-span serpent- } \\
\text { headed spear }\end{array}$ \\
\cline { 2 - 3 } & long snake-like spear & $\begin{array}{l}\text { eighteen-span snake- } \\
\text { headed spear }\end{array}$ \\
\cline { 2 - 3 } & mighty spear & $\begin{array}{l}\text { eighteen-span snake- } \\
\text { headed spear }\end{array}$ \\
\cline { 2 - 3 } & long spear & $\begin{array}{l}\text { eighteen-span } \\
\text { headed spear }\end{array}$ \\
\hline \multirow{2}{*}{ 蛇矛 } & $\begin{array}{l}\text { terrible serpent-like- } \\
\text { spear }\end{array}$ & snake-lance \\
\hline 丈八矛 & Omission & eighteen-span spear \\
\hline
\end{tabular}

In T1, the length of this weapon ("丈八") is mentioned only in its debut, with later terms modified by words like "long", "mighty" and "terrible" to create a perceptual image; T2 keeps the length information by using "eighteen-span" in all terms that contain "丈八". In this sense, T2 tries to stay closer to the original and keeping as much information as possible in the translated text, while $\mathrm{T} 1$ simplifies the information contained in the original and manages to make the translation more understandable for target readers. both versions prefer to nominate them formally, though differences may exist in their methods adopted.

Example 2:

ST：曹操有宝剑二口，一名"倚天"，一名"青釭"，……(第四十 一回)

T1: Ts'ao Ts'ao had two swords, one called I-t'ien (Trust in God) and the other Ch'ing-kung.

T2: Now, Cao Cao had two swords of exceptional value. One was called Heaven's Prop, the other Black Pommel.

In San Guo Yan Yi, the name of a weapon may carry special meanings given by its maker or owner. In the above example, "倚天" indicates the sword is so powerful that sky equals its backrest, while "青釭" refers to the color of the sword's parts. T1 adopts transliteration for the two weapons, successfully creating an exotic flavor in the rendition. What's more, "I-t'ien" is also literally translated into "Trust in God", aiming to make it understandable for target readers. T2 gives up the acoustical effect by rendering them literally into "Heaven's Prop" and "Black Pommel".

In addition, "天", as a cultural symbol, reflects the worldview contained in a certain language. Brewitt-Taylor concretizes "天" into "God", a word which has strong religious significance in the West, while Roberts keeps the image of "天" by choosing a more neutral word: "Heaven". Here, it's safe to assume that T1 is more domesticated in translating culture-loaded items embedded in weapons by staying closer to the target culture.

Example 3:

ST: 普净以手举所佩戒刀, 以目视关公。（第二十七回）

T1: ..., at the same time lifting the priest knife which he wore at his side and looking meaningfully at Kuan Yu.

T2: Signaling with his eyes, he raised the monastic knife symbolizing the sacred renunciations.

In Example 3, the man called Pu Jing is a monk who has saved Guan Yu's life by informing him of the malicious intent of Cao Cao's subordinate. To make the rendition more acceptable to western readers, $\mathrm{T} 1$ changes the identity of $\mathrm{Pu}$ Jing from monk to priest, and his weapon to "priest knife". In comparison, Roberts retains the Buddhist system in T2, and more than that, he also explains the symbolized meaning of " 戒刀" in Chinese Buddhism, from which readers can get more information about this piece of weapon. This example helps to confirm the assumption above: in translating the cultural side of weapons, T1 adjusts the original to fit the target culture and cater to the target readers, while T2 tends to keep the original meaning and let target readers to step towards those cultural items.

To sum up, T1 is more domesticated in translating the cultural elements of weapons, and the cultural connotations of weapons are explicitly and liberally translated. In Roberts' case, the cultural connotations of weapons are faithfully reproduced in English. T2 is more foreignized in translating the cultural elements of weapons, thus more informative for 
shortening or directly omitting military attires. By doing so, readers can skip over the complicated depiction to get a direct and overall impression on the military attires. This enhances the acceptability of the translated text among the ordinary readers. Roberts faithfully translates those terms into English, with few omitted. By doing so, scholarly readers to get a detailed picture of ancient Chinese attires, with the flavor and structure of the original text maintained to the largest extent.

\section{STRATEGIES FOR TRANSLATING Military STRATEGIES}

As is known to all, the military strategies in San Guo Yan $Y i$ are rich in historical deposits and profound in cultural connotations. A seemingly simple strategy may draw froth an intriguing history. More often than not, Brewitt-Taylor translates them in a free and explicit way, making it easier for foreign readers to understand. Through leaning towards the western world in both language and culture, he manages to make T1 read more like an indigenous novel. On the other hand, Roberts translates those strategies faithfully as he usually does. For military strategies with historical background, he will add notes to provide supplementary information for readers who are interested yet unfamiliar with the unique aspects of those strategies.

\section{Example 6}

ST: 来日必用拖刀计, 背砍赢之。(第五十三回)

ST: 黄盖望见穿㖓红袍者下船, 料是曹操，乃催船速进，…… (第四十九回)

T1: Huang Kai seeing a handsomely robed person gets into a small boat guessed it must be Ts'ao Ts'ao and pursued.

T2: Huang Gai had spotted someone in a scarlet battle gown lowering himself into a boat and, surmising it was Cao Cao, made for him

Example 5:

$\mathrm{ST}$ : 青龙宝刀灿霜雪, 数䴔战袍飞蛱蝶。(第五回)

T1: Black Dragon his sword shone white as hoar frost in the sunlight, His bright colored fighting robe fluttered like butterfly wings.

T2: His dragon blade as dazzling as fresh snow, His war coat, parrot-hued, a swirl below.

In the two examples above, Roberts translates "绿红袍" and "鹦鹉战袍" literally into "scarlet battle gown" and "war coat, parrot-hued", perfectly reproducing the original text in English. Brewitt-Taylor ignores the specific color and uses "handsomely" and "bright colored" to show the overall impression given by the attires. With details omitted, the translation presents readers with a more direct visual stimulus. Translators' personal comprehension can help to facilitate the process of reading for target readers. However, it needs to point out that, translators should make sure their personal comprehension is appropriate and related to the original as they render those terms liberally.

To summarize, Brewitt-Taylor makes the translated text more natural and simplifies readers' receiving process by
T1: He determined that in the next encounter he would use a feint (or "Parthian" stab) and so overcome him.

T2: Tomorrow I'll have to use the 'trailing sword trick' and get him while he gives chase.

Example 7

ST: 孔明日："此乃假途灭虢之计也。……" (第五十六回)

T1: "This is the ruse known as 'borrow a road to exterminate Kuo.'..."

T2: "...using the ancient ruse of 'passing through on the pretext of conquering Guo.'..."1

As a common trick in ancient Chinese one-to-one fight, " 拖刀计" goes in two steps: firstly, one pretends to be defeated and flees with his weapon trailed behind, so as to lure his opponent into chase; secondly, when his opponent falls into the trap, he will seize the opportunity to give a turnaround cut. The turnaround movement is very similar to the "Parthian" shot or stab. Brewitt-Taylor considers the relation between the two and chooses to erase the Chinese characteristics of "拖刀计" by replacing it with an existing western term. Compared with introducing a new term into English, this "offer of information" is much easier for foreign readers to accept. However, this kind of domesticated translation may give readers a false impression that warriors

In the Spring and Autumn period the Kingdom of Jin asked the Kingdom of Yu to permit its troops to pass through in order to attack the Kingdom of Guo. On their way back, the Jin army annexed Yu. See Zuozhuan, "Xigong," year 5. 
[5] Brewitt-Taylor, C.H. Romance of the Three Kingdoms[M]. Hong Kong: Turtle Publishing, 2002.

in the Period of Three Kingdoms knew the Parthian fighting movements. In this case, it's better to translate "拖刀计" literally as T2 does, and add background information for the "Parthian stab" as a useful reference for foreign readers.

In Example 7, the origin of the strategy called "假途灭號之 计" can be traced back to the Spring and Autumn Period. In order not to influence the smooth reading, Brewitt-Taylor gives up on detailed explanation by simply translating it into "the ruse known as 'borrow a road to exterminate Kuo'". However, for translators like Moss Roberts who pursue more than adequacy in rendition, the note that carries background information is added to explain the origin of the strategy.

In summary, for the complicated military strategies in San Guo Yan Yi Brewitt-Taylor chooses to translate them explicitly and liberally, so as to facilitate the receiving process in the target contexts. Roberts translates those strategies faithfully as he usually does. For military strategies with historical background, he will add notes to provide supplementary information for readers who are interested yet unfamiliar with the unique aspects of those strategies.

\section{CONCLUSION}

As the study shows, the two translators differ in choosing strategies for translating military terms in San Guo Yan Yi. At the same time, both have their own preferences or tendencies to adopting strategies for translating different groups of military terms to fulfill their own specific goals. In translating the cultural elements of weapons, Brewitt-Taylor prefer to be more domesticated, and the cultural connotations of weapons are explicitly and liberally reproduced, while Roberts tends to be more foreignized, and the cultural connotations of weapons are faithfully reproduced. As far as the translation of military attires is concerned, BrewittTaylor makes the translated text more natural and simplifies readers' receiving process by shortening or directly omitting military attires, while Roberts faithfully translates those terms into English with few omitted. When it comes to the translation of military strategies, Brewitt-Taylor chooses to translate complicated military strategies explicitly and liberally, so as to facilitate the receiving process in the target contexts, while Roberts translates such military strategies faithfully as he usually does. For military strategies with historical background, Roberts will add notes to provide supplementary information for readers who are interested yet unfamiliar with the unique aspects of those strategies.

\section{REFERENCES}

[1] Guo Yu, Luo Xuan-min. A Fine Example of Scholarly Translation Moss Roberts' Translation of Sanguoyanyi and Its Reception[J]. Foreign Language Research, 2015 (1): 101-104.

[2] Chen Tian. A Study of English Translation of Culture-specific Items in San Guo Yan Yi[D]. Hunan Normal University, 2014.

[3] Wang Shirong. A Descriptive English Translation Study on the Culture-specific Items in "Three Kingdoms"[D]. Wuhan University, 2013.

[4] Ye Xicong. A Comparative Corpus-aided Study on the Translation of the Words for Wars in San Guo Yan Yi[D]. Dalian Maritime University, 2011.
[6] Roberts, M. Three Kingdoms[M]. Beijing: Foreign Languages Press, 2000. 